ISSN electrónico: $1885-5210$

DOI: https://doi.org/10.14201/rmc20211717784

\title{
PANDEMIAS FICTICIAS. CONTAGIO: FICCIÓN O UNA NUEVA REALIDAD
}

\author{
Fictional pandemics. Contagion fiction or new reality
}

Diana ORTIZ-QUIROGA ${ }^{1}$, Estephania CANDELO ${ }^{2}$, Yoseth ARIZA-ARAUJO ${ }^{1}$, Harry PACHAJOA ${ }^{1}{ }^{2}$

${ }^{1}$ Centro de Investigación en Anomalías congénitas y Enfermedades Raras, CIACER. Facultad de Ciencias de la Salud. Universidad Icesi. Cali (Colombia).

${ }^{2}$ Fundación Clínica Valle del Lili. Cali (Colombia).

Correspondencia: Diana Marcela Ortiz Quiroga.

Correo electrónico: dmortiz@icesi.edu.co

Ficha técnica

Título: Contagio.

Título original: Contagion.

País: Estados Unidos, Emiratos Árabes.

Año: 2011.

Director: Steven Soderbergh.

Música: Cliff Martínez.

Fotografía: Steven Soderbergh.

Montaje: Stephen Mirrione.

Guion: Scott Z. Burns.

Intérpretes: Matt Damon, Kate Winslet, Laurence Fishburne, Marion Cotillard, Jude Law, Gwyneth Paltrow, Bryan Cranston, Jennifer Ehle, Sanaa Lathan, Elliott Gould, John Hawkes, Enrico Colantoni, Chin Han, Monique Gabriela Curnen, Josie Ho, Chui Tien-You, Daria Strokous, Griffin Kane, Yoshiaki Kobayashi, Grace Rex, Armin Rohde,
Rebecca Spence, Andrew White, Larry Clarke, Anna Jacoby-Heron, Jimmy Chung, Demetri Martin, John Hines, Joshua Weinstein, Dan Aho, Randy Lowell, Raymond Tsang, Jim Ortlieb, Annabel Armour, Kara Zediker, Laura T. Fisher, Mary Beth Dolan, Jason Babinsky, Sanjay Gupta, Dan Flannery.

Color: color.

Duración: 106 minutos.

Género: acción, ciencia ficción, thriller. Pandemias. Idioma original: inglés.

Productores: Warner Bros. Pictures, Regency Enterprises, Imagenation Abu Dhabi FZ, Participant Media, Double Feature FilmS.

Premios: ganadora del Golden Trailer 2012, en la categoría de mejor thriller y del Hollywood Film Award 2011, en la categoría editor del año. 
Sinopsis: «De repente, sin saber cuál es su origen, aunque todo hace sospechar que comienza con el viaje de una norteamericana a un casino de Hong Kong, un virus mortal comienza a propagarse por todo el mundo. En pocos días, la enfermedad empieza a diezmar a la población. El contagio se produce por mero contacto entre los seres humanos. Un thriller realista y sin efectos especiales sobre los efectos de una epidemia» (FilmAffinity).

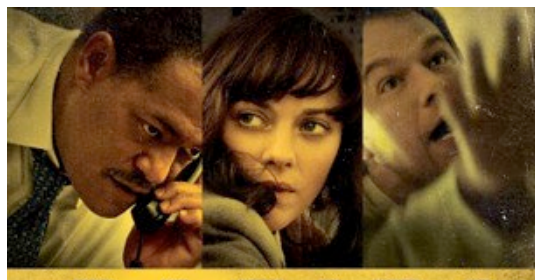

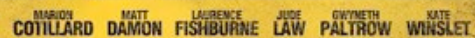
WADA SE EXPANDE CONO EL MIEDO CONTAG I 0

\section{Enlaces:}

Imdb: https://www.imdb.com/title/tt1598778/ FilmAffinity: https://www.filmaffinity.com/es/ film145476.html

\section{Tráiler en español}

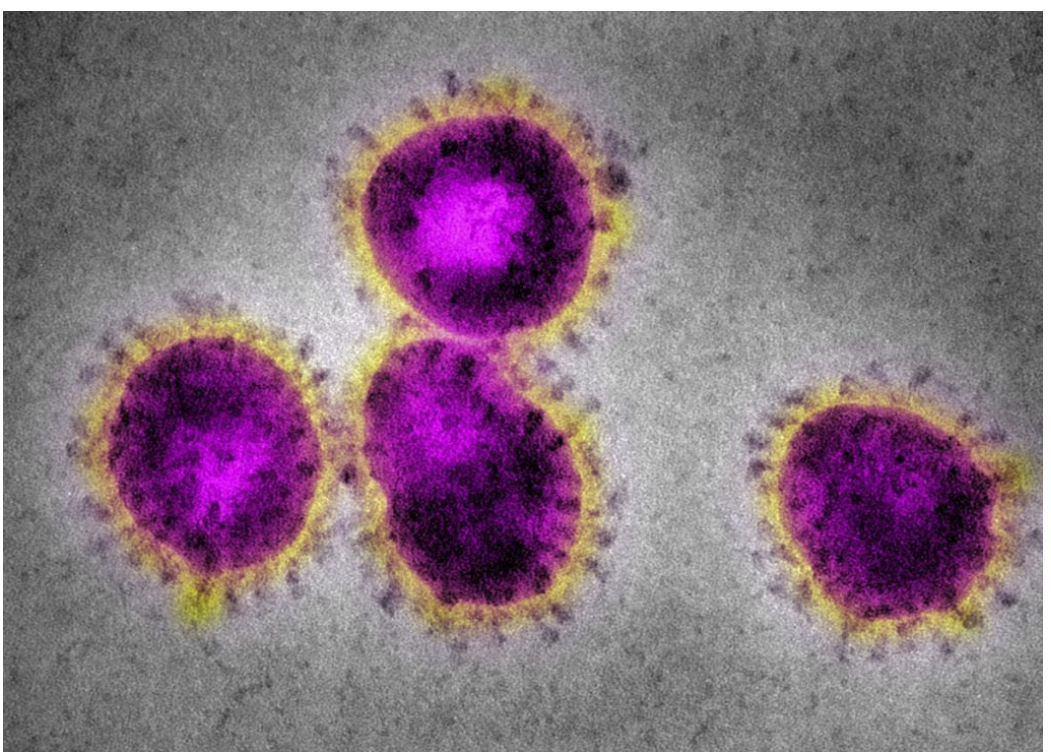

1. El virus MEV-1.
Cartel español

Acción: alrededor de 2010 (Hong Kong, Chicago, Atlanta, Minneapolis). 
PANDEMIAS FICTICIAS. CONTAGIO: FICCIÓN O UNA NUEVA REALIDAD

DIANA ORTIZ-QUIROGA, ESTEPHANIA CANDELO, YOSETH ARIZA-ARAUJO, HARRY PACHAJOA

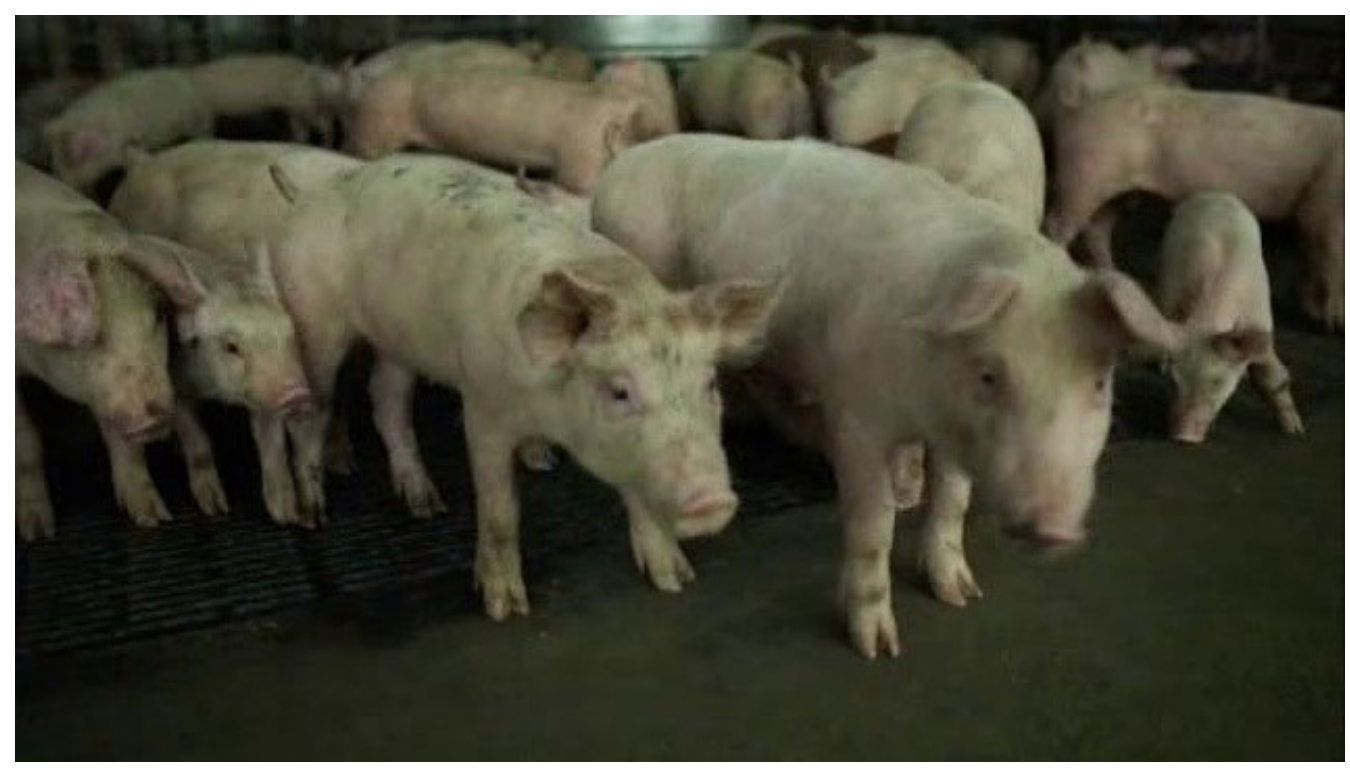

2. Fuente de Origen: Zoonosis. Hospedador definitivo.

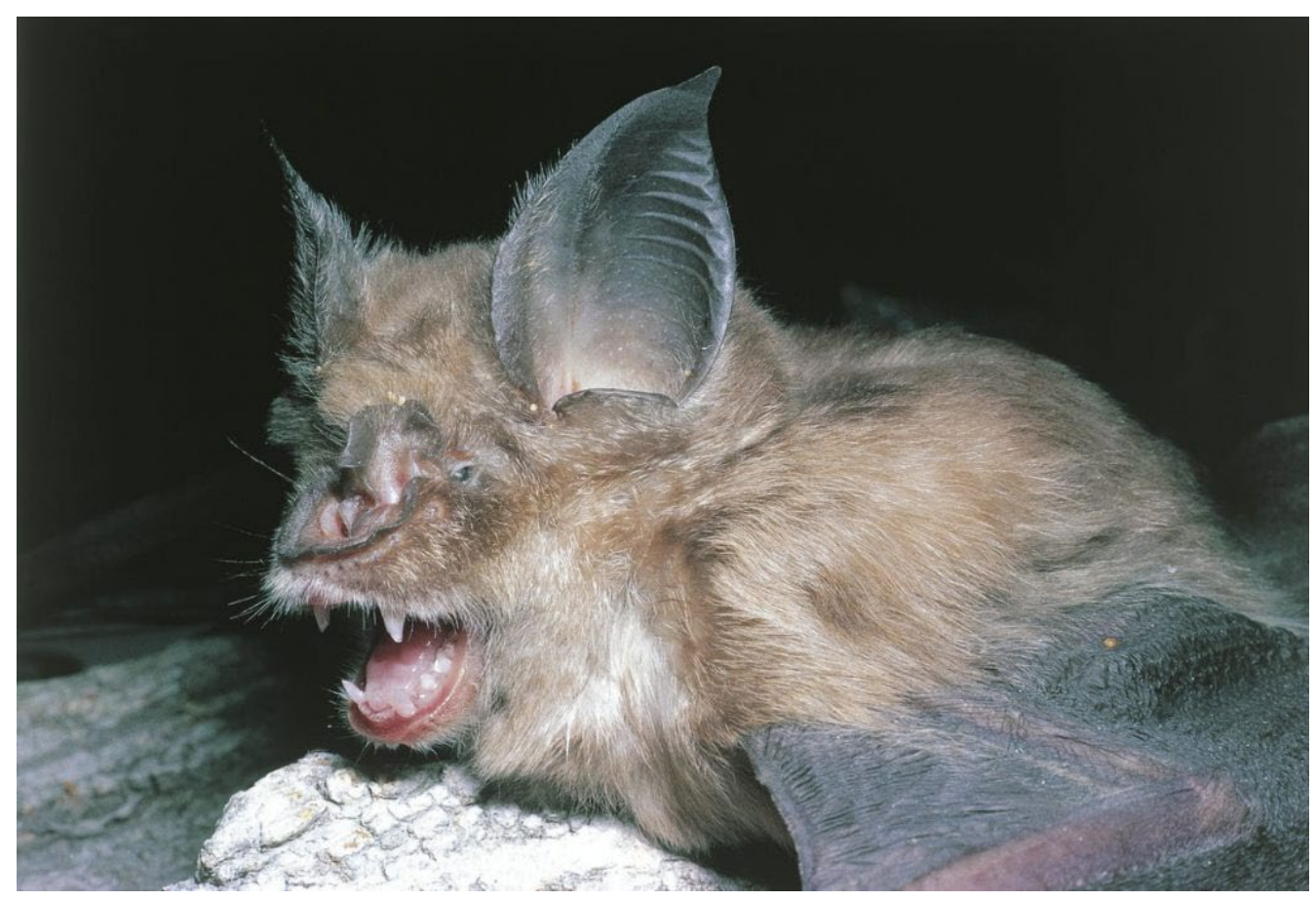

2.1 Hospedador intermedio.

Rev. Med. Cine. 2021; 17 (1), 77-84 Ediciones Universidad de Salamanca / @@@

J. Med. Mov., 2021; 17 (1), 77-84 [ 79 ] 
PANDEMIAS FICTICIAS. CONTAGIO: FICCIÓN O UNA NUEVA REALIDAD

DIANA ORTIZ-QUIROGA, ESTEPHANIA CANDELO, YOSETH ARIZA-ARAUJO, HARRY PACHAJOA

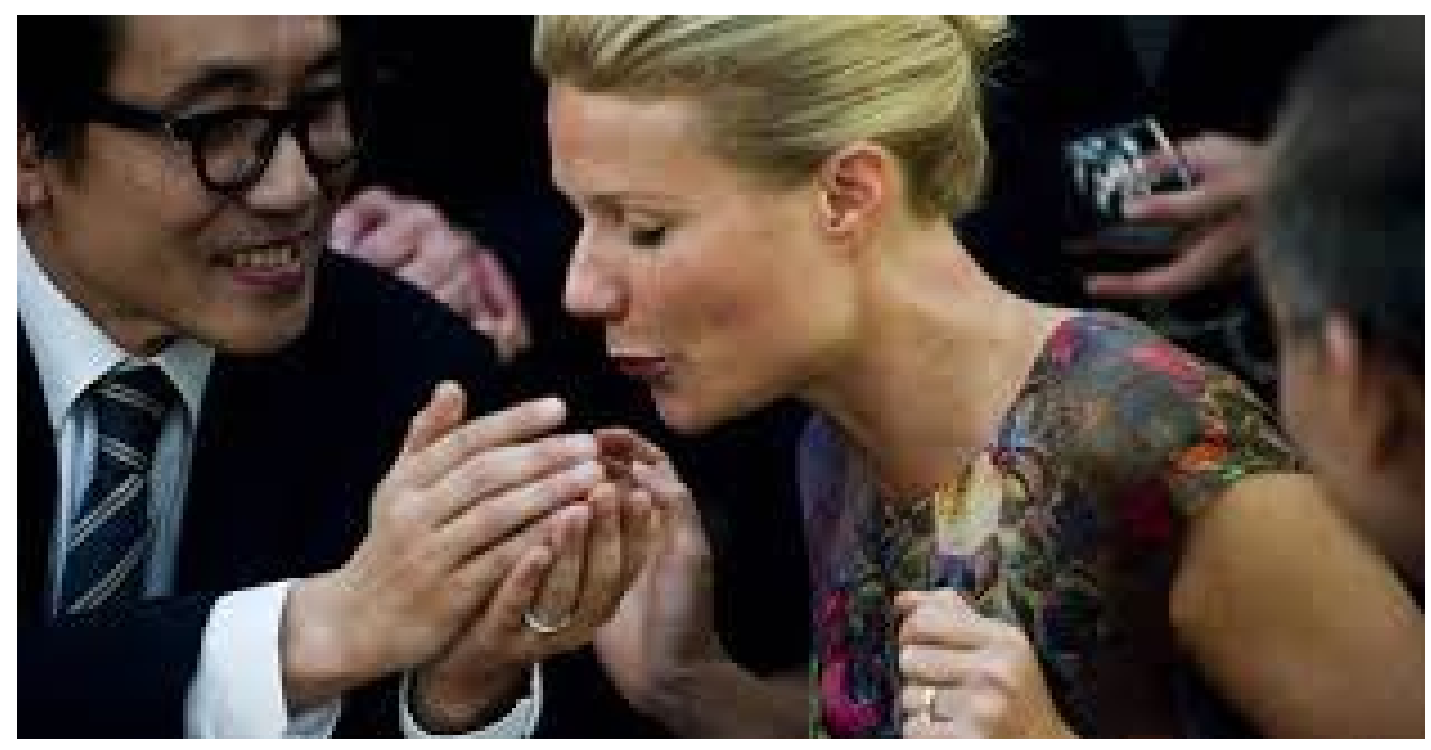

3. Formas de transmisión: el contacto con persona infectada o con superficies tocadas por personas infectadas.

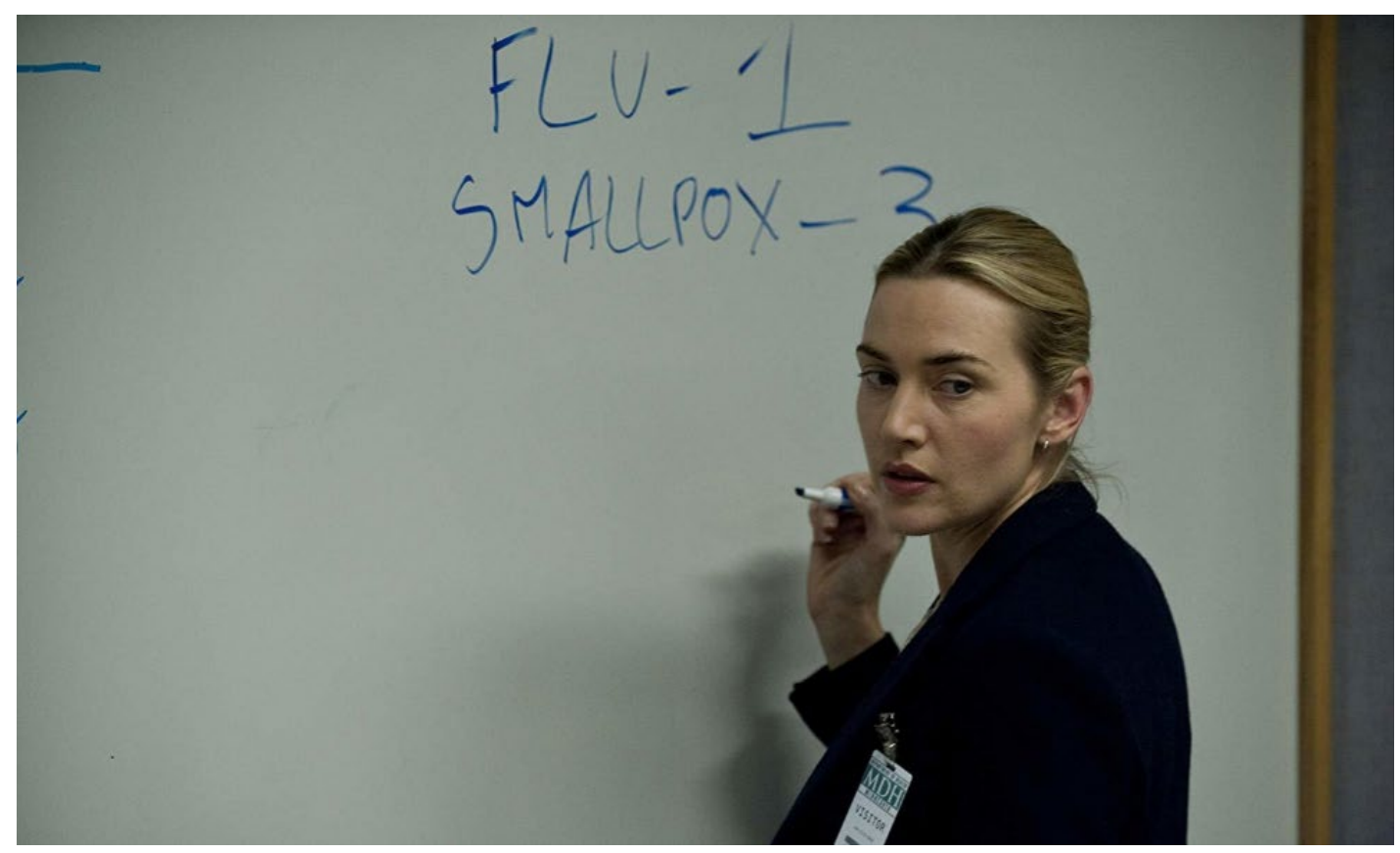

4. Tasa de reproducción.

Rev. Med. Cine. 2021; 17 (1), 77-84 Ediciones Universidad de Salamanca / @@@

J. Med. Mov., 2021; 17 (1), 77-84 [ 80 ] 
PANDEMIAS FICTICIAS. CONTAGIO: FICCIÓN O UNA NUEVA REALIDAD

DIANA ORTIZ-QUIROGA, ESTEPHANIA CANDELO, YOSETH ARIZA-ARAUJO, HARRY PACHAJOA

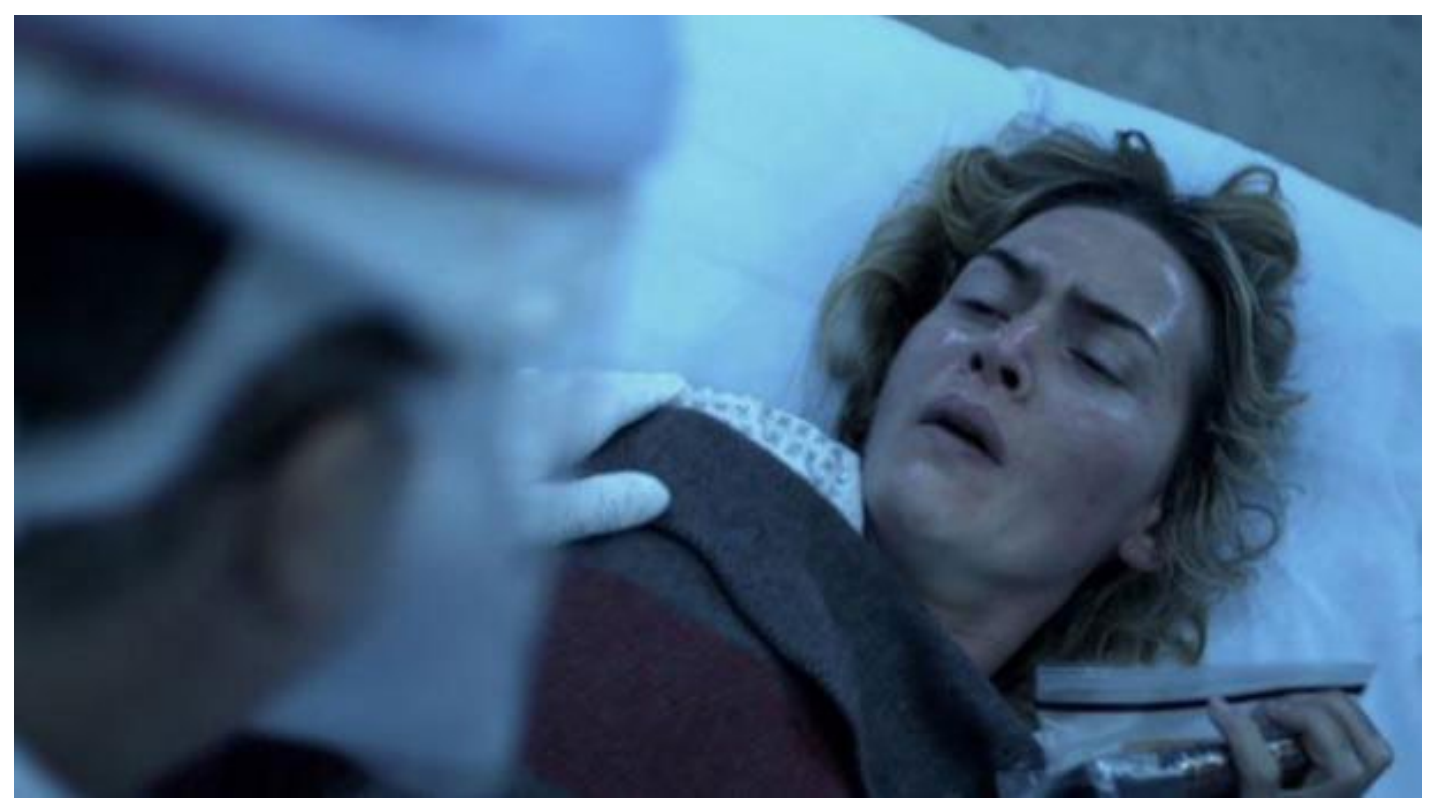

5. Manifestaciones clínicas: fiebre, dolor de garganta, tos, sudoración, malestar general.

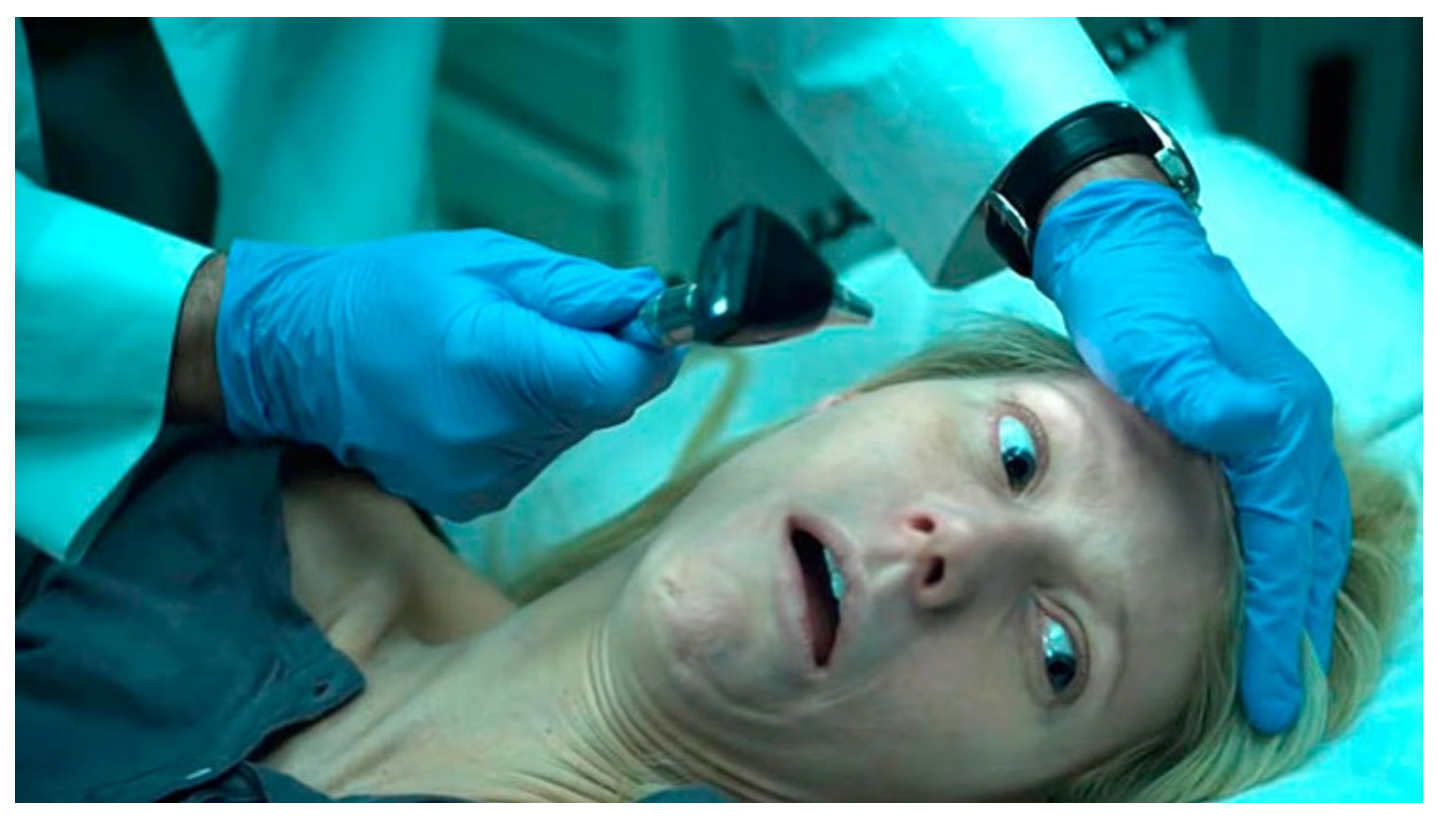

5.1 Status convulsivo.

Rev. Med. Cine. 2021; 17 (1), 77-84 Ediciones Universidad de Salamanca / @@@

J. Med. Mov., 2021; 17 (1), 77-84 [81] 
PANDEMIAS FICTICIAS. CONTAGIO: FICCIÓN O UNA NUEVA REALIDAD

DIANA ORTIZ-QUIROGA, ESTEPHANIA CANDELO, YOSETH ARIZA-ARAUJO, HARRY PACHAJOA

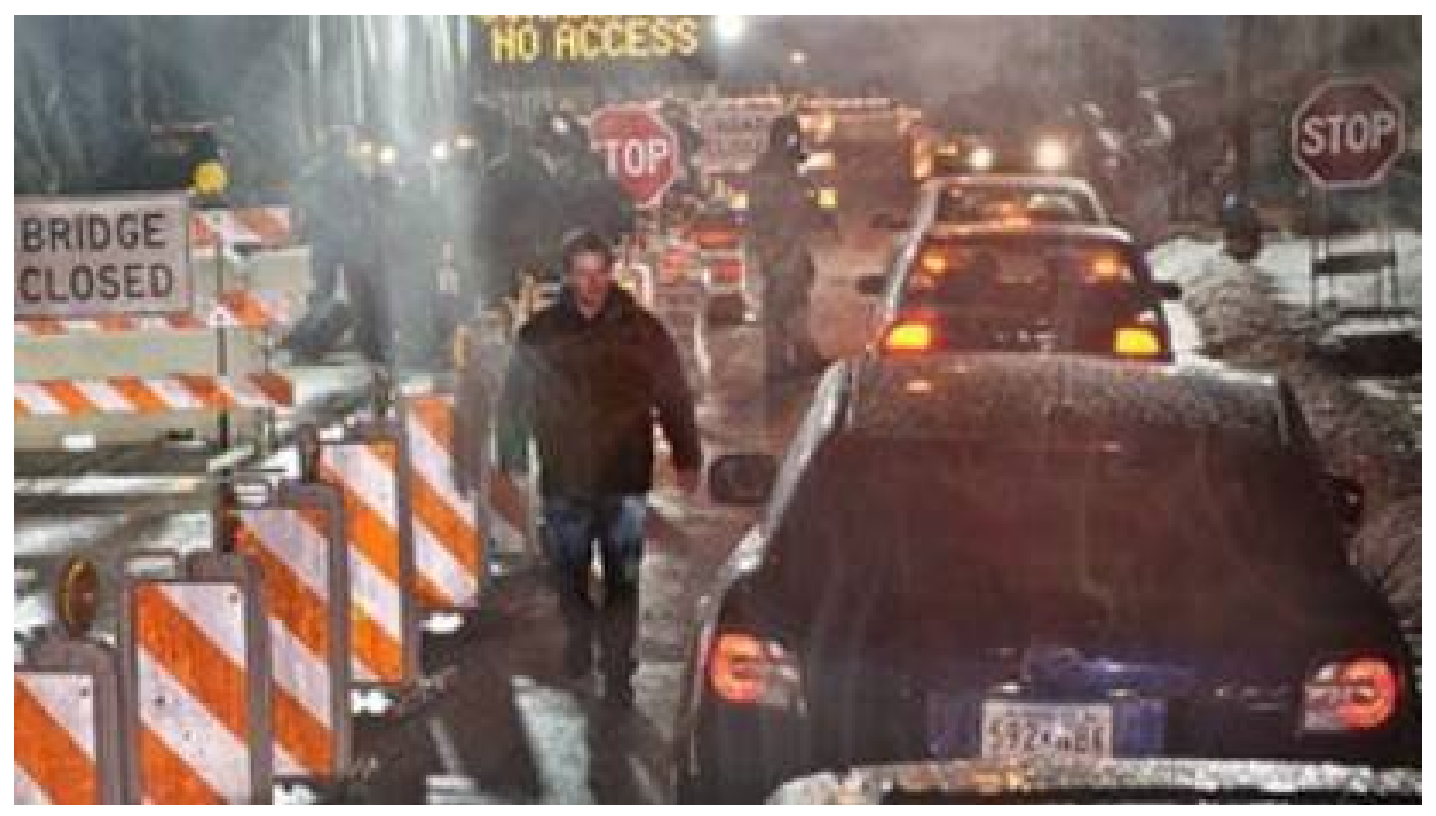

6. Medidas de contención: cuarentena y cierre de fronteras.

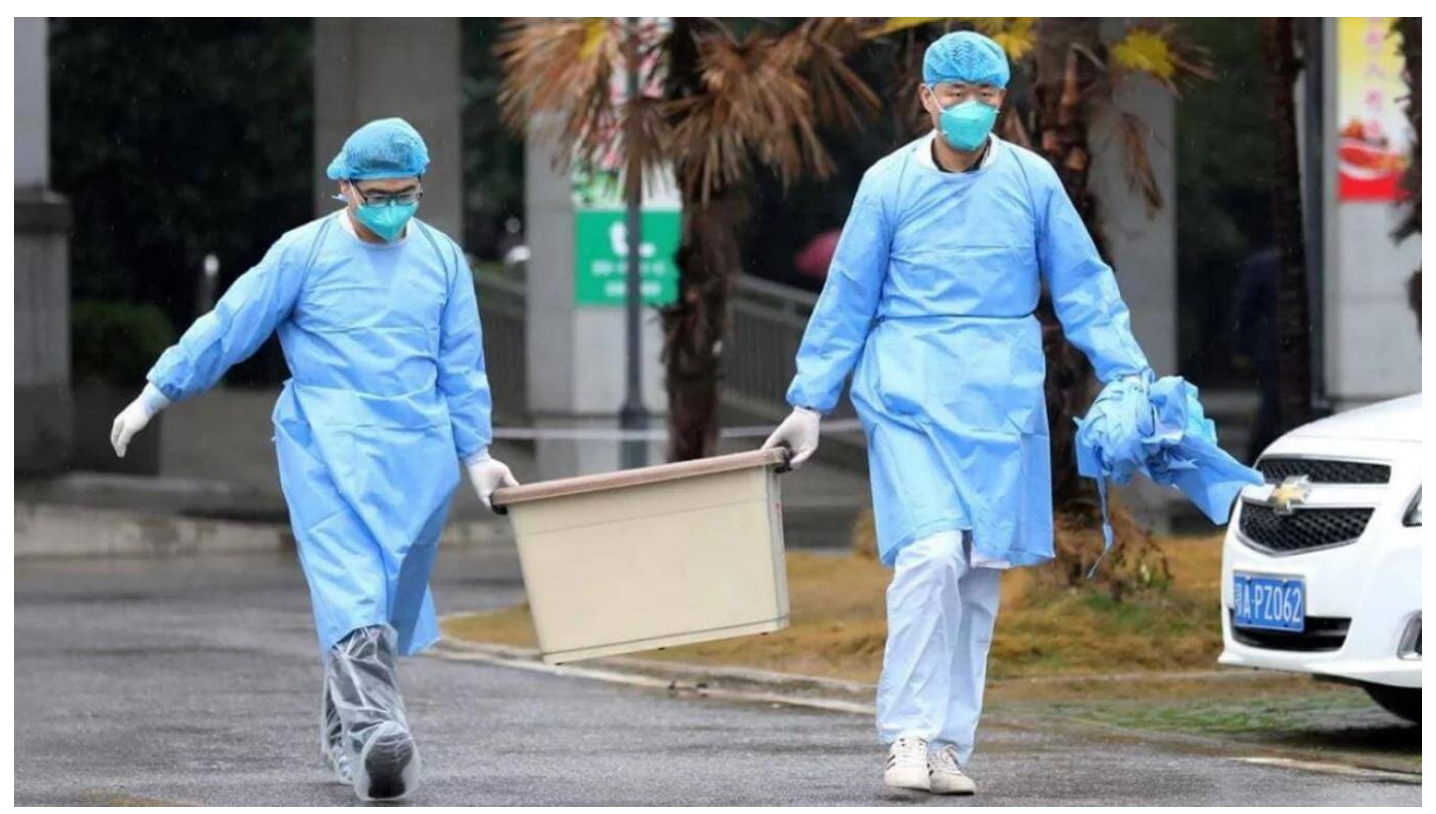

6.1 Uso de tapabocas, guantes y trajes aislantes.

Rev. Med. Cine. 2021; 17 (1), 77-84 Ediciones Universidad de Salamanca / @@@

J. Med. Mov., 2021; 17 (1), 77-84

[82 ] 
PANDEMIAS FICTICIAS. CONTAGIO: FICCIÓN O UNA NUEVA REALIDAD

DIANA ORTIZ-QUIROGA, ESTEPHANIA CANDELO, YOSETH ARIZA-ARAUJO, HARRY PACHAJOA

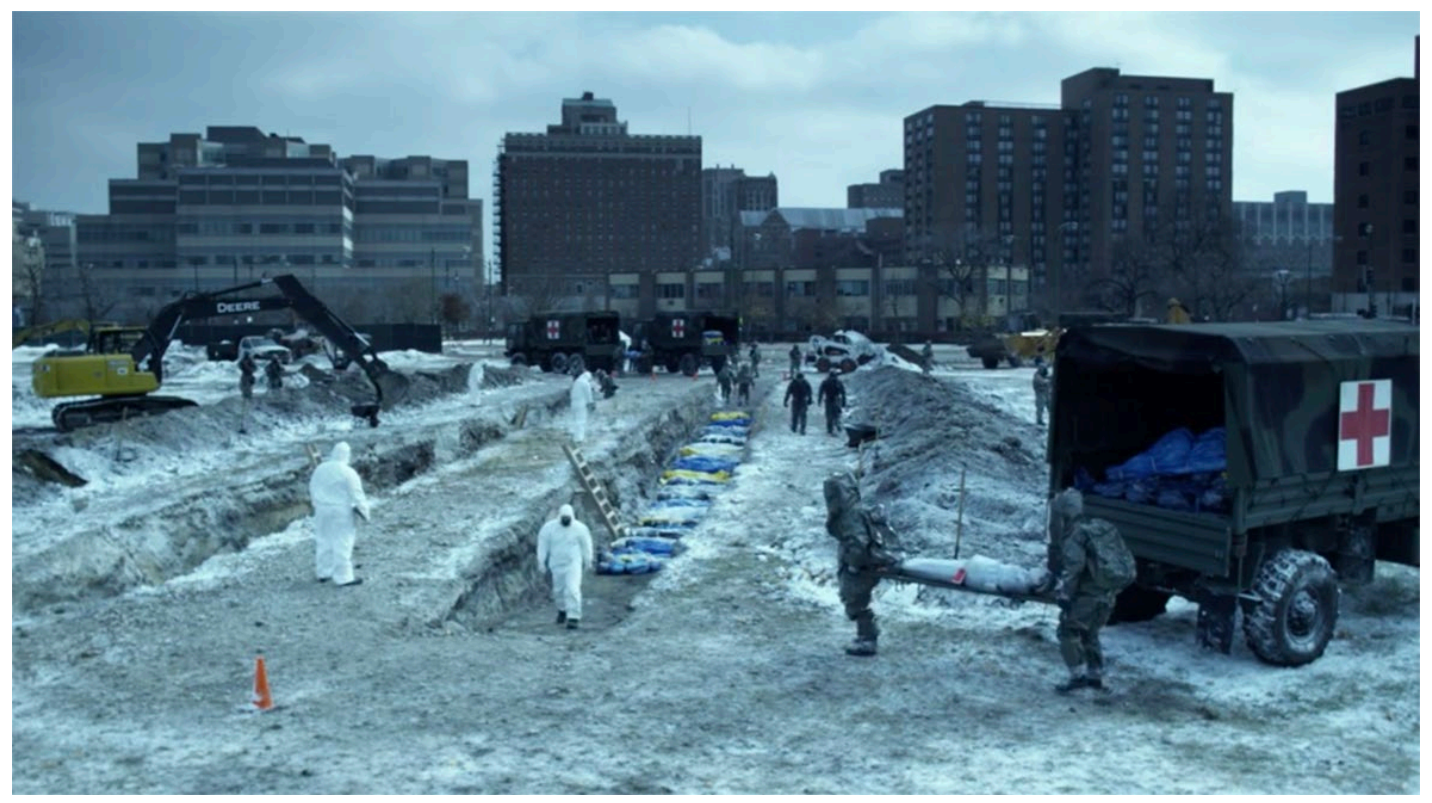

6.2 Cremación de cadáveres.

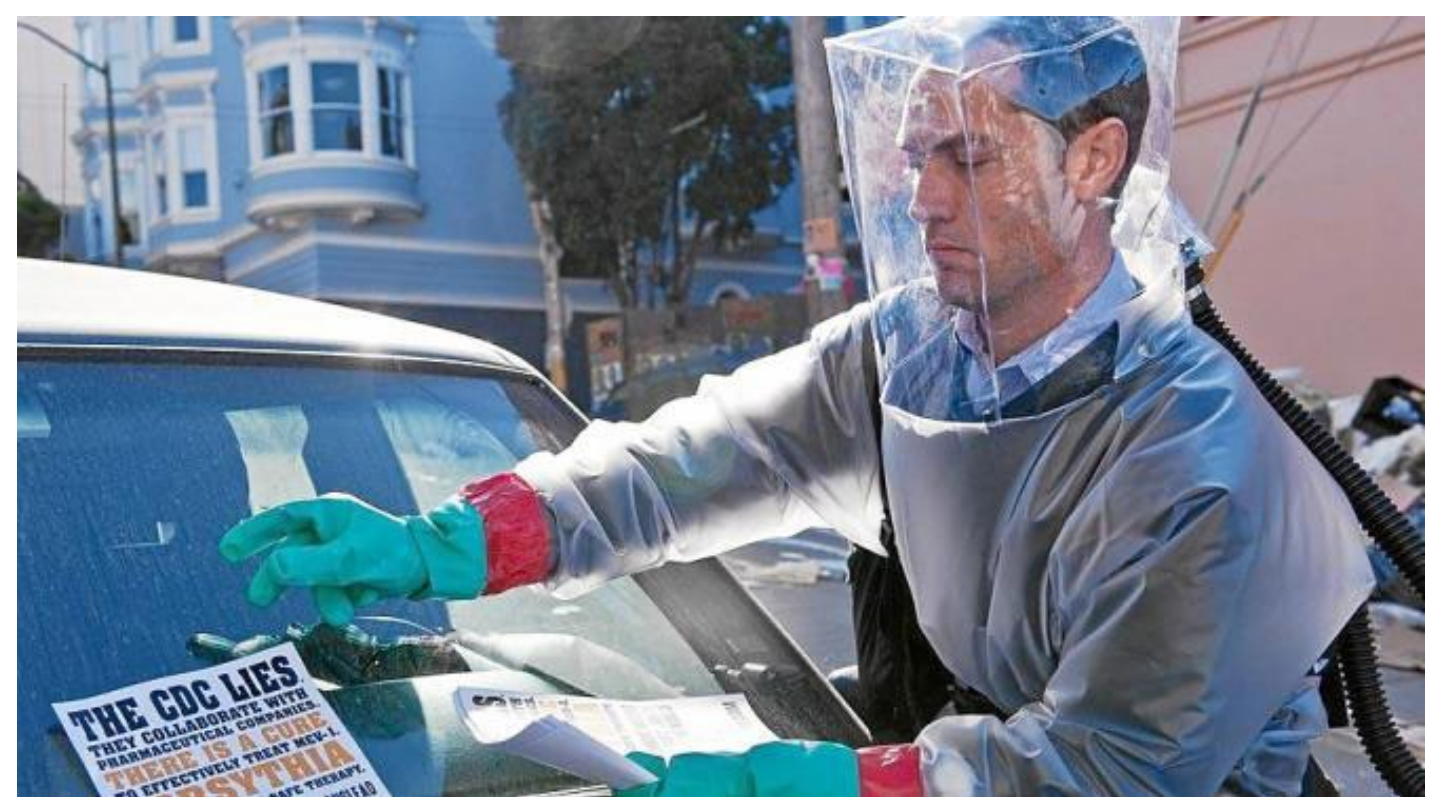

7. Reacciones: difusión de información falsa o desinformación.

Rev. Med. Cine. 2021; 17 (1), 77-84 Ediciones Universidad de Salamanca / @@@

J. Med. Mov., 2021; 17 (1), 77-84 
PANDEMIAS FICTICIAS. CONTAGIO: FICCIÓN O UNA NUEVA REALIDAD

DIANA ORTIZ-QUIROGA, ESTEPHANIA CANDELO, YOSETH ARIZA-ARAUJO, HARRY PACHAJOA

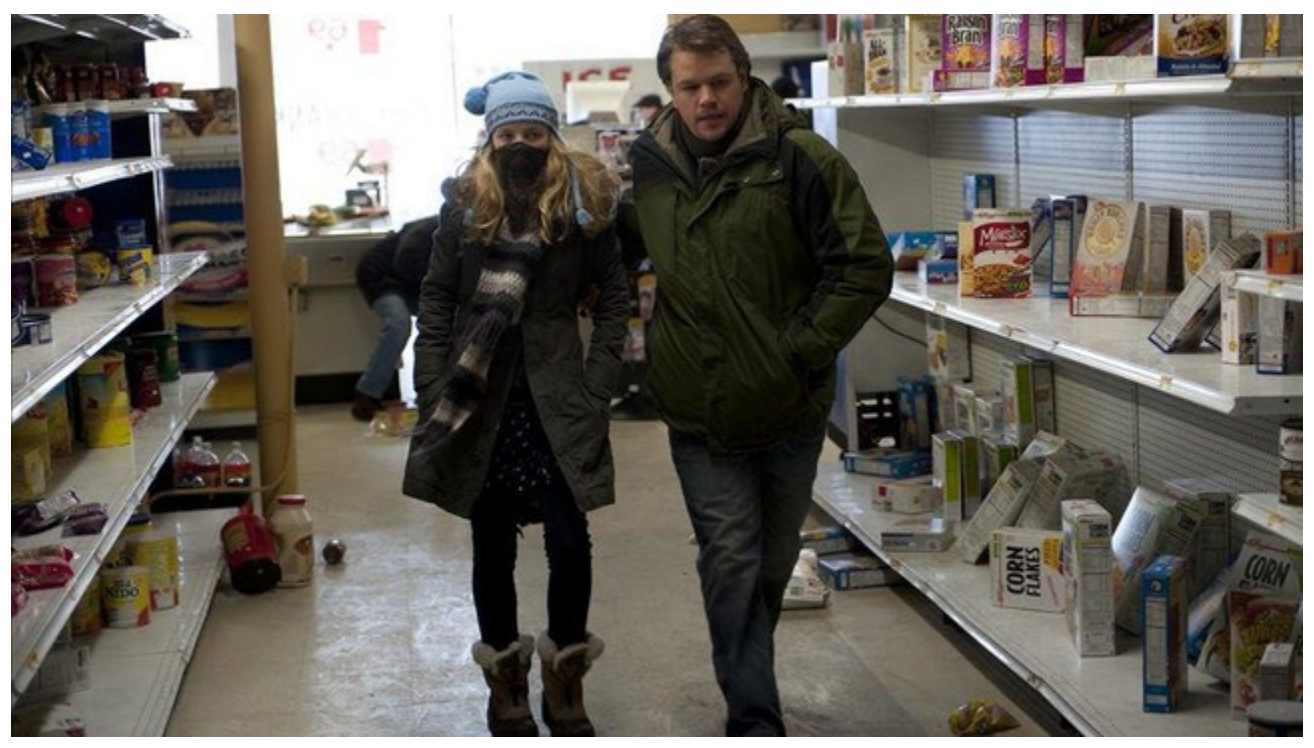

7.2. Pánico: compras sin sentido.

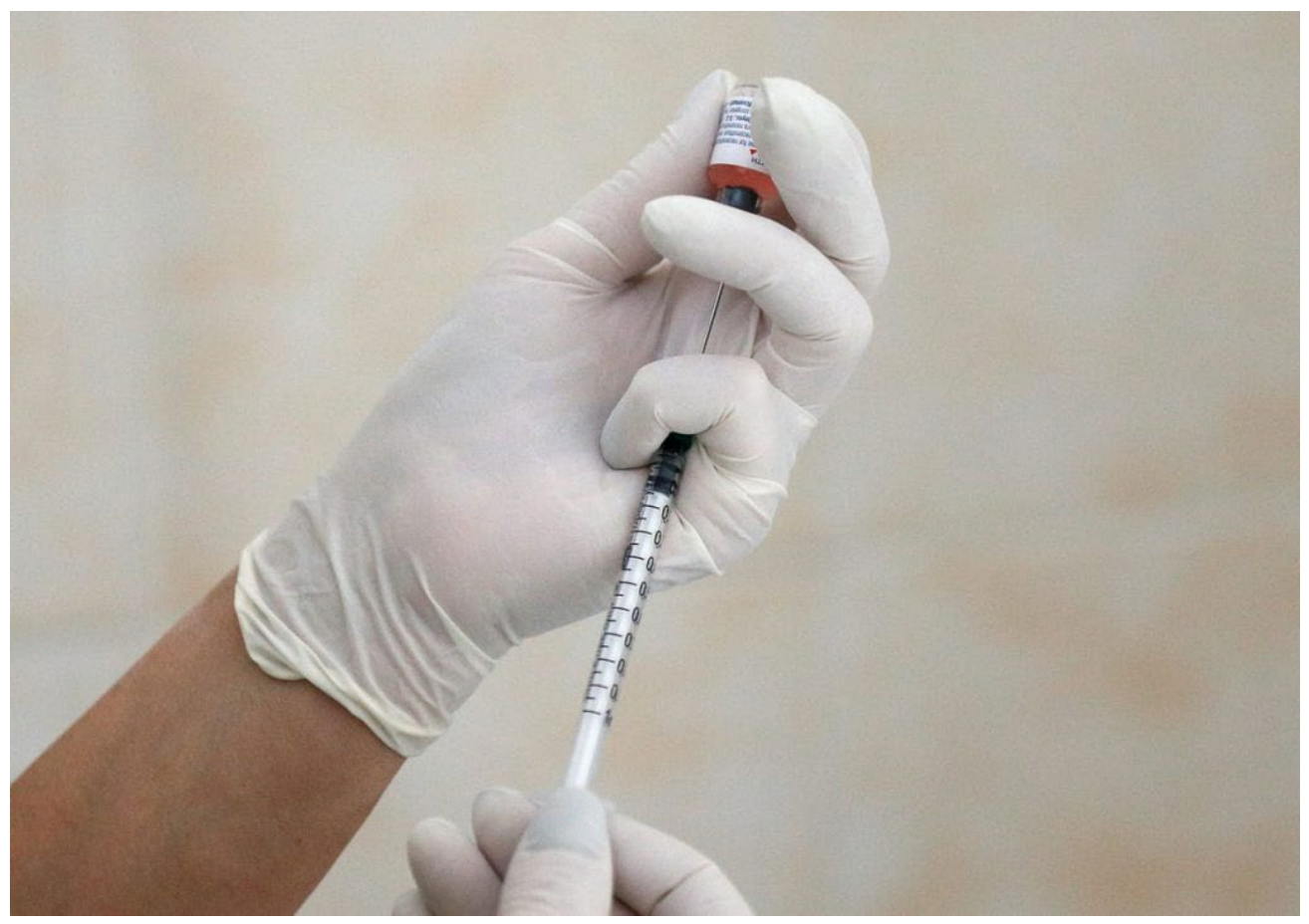

8. Tratamiento: la vacuna. 